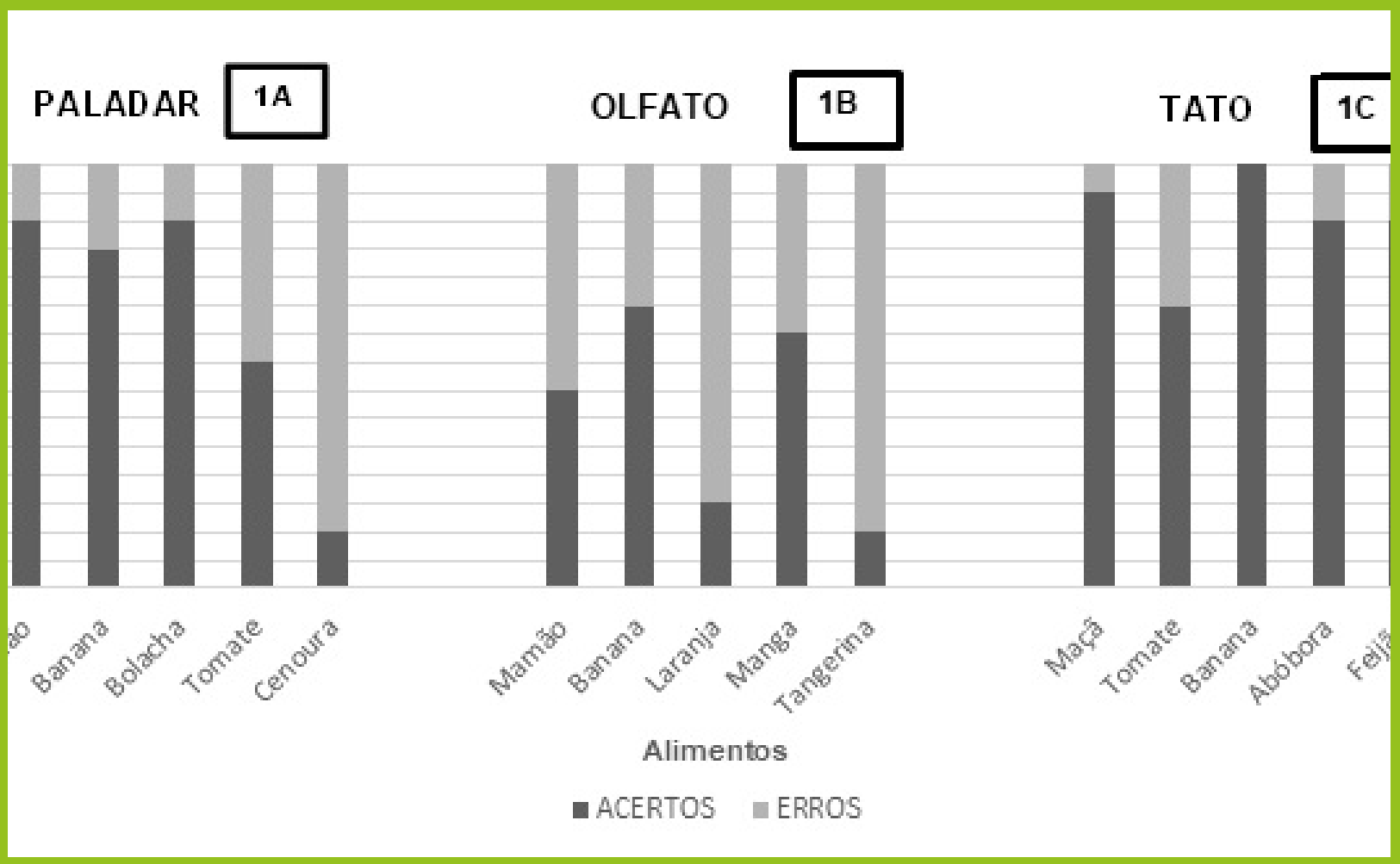

\title{
Aplicação da Educação Alimentar e Nutricional no contexto de uma escola para pessoas com deficiência
}

Johnny Trindade de Assis - johnnydno.geo@gmail.com¹

Lynnara Rodrigues Carvalho - Iynnara.rodrigues@hotmail.com²

Caroline Roberta Freitas Pires - carolinerfpires@uft.edu.br³

Diego Neves de Sousa - diego.sousa@embrapa.br ${ }^{4}$

\section{RESUMO}

A Educação Alimentar e Nutricional (EAN) tem por finalidade colaborar com a promoção e a melhoria na qualidade da saúde baseada numa alimentação saudável e adequada. Diante disso, o objetivo deste artigo é relatar a aplicação de ações de EAN que visou estimular e desenvolver o interesse pelo consumo de alimentos saudáveis nos escolares inseridos na Associação de Pais e Amigos dos Excepcionais (APAE) de Palmas-TO, utilizando diferentes estratégias de atividades lúdicas, com foco no estímulo para adoção de hábitos alimentares saudáveis. Durante as atividades, os alunos demonstraram certa dificuldade quanto ao reconhecimento de alimentos importantes para uma alimentação saudável devido às peculiaridades desses escolares. No entanto, a aplicação de ações de EAN se confirmou como uma importante ferramenta de aprendizagem e promoção da saúde.

PALAVRAS-CHAVE: intervenção; alimentação saudável; ensino-aprendizagem.

1 Estudante do Curso de Nutrição da Universidade Federal de Tocantins.

2 Estudante do Curso de Nutrição da Universidade Federal de Tocantins.

3 Professora da Universidade Federal de Tocantins.

4 Doutor em Desenvolvimento Rural pela Universidade Federal do Rio Grande do Sul. Analista da Embrapa Pesca e Aquicultura. 


\title{
Applying Food and Nutrition Education in the context of a school for students with disabilities
}

\begin{abstract}
Food and Nutrition Education (FNE) aims to collaborate to the promotion and improvement of the quality of health based on a healthy and adequate diet. Therefore, the objective of this article is to report the application of FNE actions which aimed to stimulate and develop the interest in the consumption of healthy foods by students enrolled in the Association of Parents and Friends of Exceptional Children (APAE) in Palmas, TO. To do so, different strategies of playful activities were used which focused on stimulating the adoption of healthy eating habits. During the activities, the students demonstrated some difficulty in the recognition of important foods for a healthy diet due to the peculiarities of the group. However, the application of EAN actions has been confirmed as an important tool for the promotion of and learning about health.
\end{abstract}

KEYWORDS: intervention; healthy eating; teaching and learning.

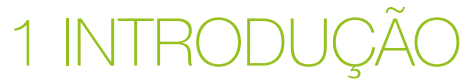

Nas últimas décadas, os seres humanos vivenciaram importantes mudanças sociais que resultaram em alterações no consumo alimentar, influenciando fortemente um padrão alimentar caracterizado por uma combinação de alimentos classificados como ultraprocessados, isto é, com altos teores de gordura, sódio e açúcar. Esses alimentos têm relação direta com o crescimento da obesidade e outras doenças crônicas e explicam, em parte, os aumentos da prevalência de sobrepeso e obesidade observados nas últimas décadas no Brasil (BRASIL, 2014). Isso justifica a importância de ações de Educação Alimentar e Nutricional (EAN) no contexto escolar, como forma de conscientização e orientação a respeito de sua aplicação na prática.

Assim, as ações que englobam a alimentação e a nutrição ganham cada vez mais relevância, tendo em vista a atual situação epidemiológica brasileira, onde se verifica o aumento de Doenças Crônicas Não Transmissíveis (DCNTs), como a obesidade, a hipertensão, o diabetes, bem como doenças cardiovasculares e de deficiências nutricionais. Tratam-se, assim, de situações que estão associadas a alimentação e a hábitos de vida que não são saudáveis (SANTOS, 2015).

No contexto educacional, o Programa Nacional de Alimentação Escolar (PNAE) ganha destaque com a Resolução no 06/2020, que dispõe sobre o atendimento da alimentação escolar aos alunos da educação básica, proporcionando a eles uma alimentação complementar e diversificada, permitindo melhorias nas condições nutricionais e na capacidade de aprender, além de proporcionar a formação de hábitos alimentares saudáveis através da distribuição de refeições no decorrer do intervalo das atividades escolares (BRASIL, 2020). 0 PNAE é gerenciado pelo Fundo Nacional de Desenvolvimento da Educação (FNDE), e atende todos os alunos matriculados em creches, pré-escolas e escolas do ensino fundamental e médio qualificadas como entidades filantrópicas ou mantidas por essas instituições, inclusive as de educação especial, como é o caso da APAE (BRASIL, 2009).

A escola é um importante espaço para a formação e o desenvolvimento dos alunos, um ambiente que confere a possibilidade de educar por meio da construção do conhecimento, fruto do confronto dos diferentes saberes, que perpassam por aqueles conhecimentos científicos veiculados pelas disciplinas e também por aqueles conhecimentos trazidos pelos alunos (e seus familiares), que expressam crenças e valores culturais próprios (BRASIL, 2009).

Nesse sentido, o PNAE pode se estabelecer como uma ferramenta pedagógica, na qual o desenvolvimento de atividades de Segurança Alimentar e Nutricional (SAN) se apoia, tendo nas escolas um ambiente estratégico e propício para assegurar o fortalecimento das ações de EAN, conforme preconizado pela Lei $\mathrm{n}$ - 13.666/2018, que inclui a transversalização desse tema no currículo escolar (CASEMIR0; FONSECA; SECCO, 2014; BRASIL, 2018).

A Educação Alimentar e Nutricional é entendida como o espaço para o conhecimento prático e contínuo, que busca promover a prática autônoma e voluntária de hábitos saudáveis a partir da utilização de métodos pedagógicos que orientam o trabalho de forma lúdica, permitindo desenvolver a criatividade e a autonomia do indivíduo em diferentes aspectos e não somente no aspecto cognitivo (MARQUES, 2012). 
A adoção de atividades lúdicas é fundamental como instrumento de recurso na EAN, essas atividades podem ser compostas por jogos cooperativos, quebra-cabeça, teatro, dentre outras técnicas que têm por objetivos não só propiciar conhecimento científico, como também assegurar o prazer no envolvimento dos alunos com a aula, influenciando de maneira efetiva no modo de vida e nos hábitos alimentares dos educandos (HEBERLE, 2011; PIRES et al., 2020). Rossi, Moreira e Rauen (2008) explanam que experiências prévias de interação contínua com o alimento influenciam nas predileções alimentares, hábitos e atitudes desenvolvidas na fase adulta, pois quanto mais precoce for seguido um estilo de vida saudável, menor será o perigo de doenças crônicas não transmissíveis no futuro.

A APAE possui um público com diferentes deficiências e, embora a maioria desses alunos esteja incluída no ensino regular ou especial, a falta de conhecimento sobre comportamentos de vida saudável, bem como a compreensão limitada das escolhas nutricionais influenciam tanto para o excesso de peso quanto para os índices de desnutrição (ZUCHETTO; MIRANDA, 2011).

Ao utilizar os fundamentos que alicerçam o campo da alimentação, a fim de suprir a necessidade de sensibilizar os alunos em relação aos cuidados alimentares, este trabalho teve por objetivo relatar a aplicação de ações de EAN que visou estimular e desenvolver o interesse pelo consumo de alimentos saudáveis nos escolares inseridos na APAE-TO, utilizando diferentes estratégias de atividades lúdicas, com foco no estímulo para adoção de hábitos alimentares saudáveis.

\section{METODOLOGIA}

O presente trabalho contempla um estudo de caráter descritivo, obtido através da prática de atividades de Educação Alimentar e Nutricional, realizadas no segundo semestre de 2017 e primeiro semestre de 2018, em uma escola de alunos especiais. 0 estudo foi conduzido por alunos matriculados no curso de nutrição da Universidade Federal do Tocantins - Campus de Palmas.

A importância desta ação extensionista na formação dos estudantes de nutrição que participaram do projeto foi enorme. Além da experiência de atuar com a temática de EAN em uma escola para pessoas com deficiência, os futuros nutricionistas colocaram em prática, em um contexto real, os conhecimentos teóricos adquiridos em sala de aula. Desta forma, tiveram que promover ações para garantir a segurança alimentar e nutricional das crianças, dos jovens e adolescentes que frequentam a APAE.

A prática extensionista permite $\mathrm{o}$ aperfeiçoamento profissional dos estudantes, com o fornecimento de subsídios que favorecem um olhar reflexivo sobre o contexto profissional, propiciando maior interação, intervenção e transformação do espaço. Além disso, a formação profissional associada a atividades de extensão amplia a compreensão sobre questões éticas e desafios profissionais, a partir do desenvolvimento de estímulos cognitivos e psicomotores, bem como de noções de cidadania (SEIXAS et al., 2008).

0 perfil da instituição de ensino onde foi realizada a atividade de extensão perpassa pelo atendimento às pessoas com deficiência intelectual e múltipla, portador da síndrome de Down, autistas, portadores de síndromes e transtornos globais do desenvolvimento, e também recebem pessoas com altas habilidades ou superdotação. A APAE do município de Palmas-TO possui um total de 68 alunos devidamente matriculados. As atividades de EAN foram realizadas com 15 alunos, com faixa etária entre 15 e 40 anos de idade, frequentes nas turmas de escolarização, Educação de Jovens e Adultos (EJA) e oficinas pedagógicas. A escolha desse número de participantes se deu por estarem presentes diariamente no ambiente escolar, sendo possível realizar todas as atividades com o mesmo público.

Para a realização das atividades de EAN na APAE, foi realizada uma reunião inicial com a coordenação pedagógica, com o intuito de apresentar o projeto e conhecer a realidade do ambiente. A partir desse momento de ambientação, foi sugerido o trabalho em conjunto com a escola para alinhar as ações de forma que elas não interferissem no cotidiano escolar. Os espaços que poderiam ser utilizados para execução das ações propostas também foram definidos.

\subsection{ETAPAS DAS INTERVENÇÕES}

0 projeto foi planejado para ser desenvolvido em quatro etapas, tal como pode ser observado abaixo:

(1) Distinção entre alimentos saudáveis e não saudáveis

(2) Lavagem correta das mãos

(3) Análise sensorial dos alimentos

(4) Elaboração de uma horta suspensa

\section{Etapa 1:}

Na primeira etapa, todos os alunos selecionados para a participação das oficinas foram encaminhados para uma sala e se sentaram, formando um semicírculo. Isso permitiu que todos conseguissem se visualizar 
no grupo e pudessem se apresentar. Inicialmente, para a realização da ação intitulada "Alimentação Saudável", dois cartazes foram fixados na parede. Os cartazes apresentavam a figura de dois indivíduos: um representando o indivíduo (eutrófico) e o outro representando um indivíduo com obesidade. É importante destacar que nem sempre a obesidade vai ser um reflexo de uma dieta alimentar problemática ou de falta de saúde. Para condução desta dinâmica, os alunos receberam um balão que continha dentro um papel com figuras diversificadas de alimentos que fazem parte do cotidiano alimentar. Cada aluno foi convidado a estourar o balão e, em seguida, recolher o papel. Em uma mesa foram colocadas figuras ampliadas dos alimentos que estavam dentro dos balões. Ao analisar o papel, o participante era convidado a se dirigir até a mesa e pegar a mesma figura. Então, de acordo com seu conhecimento a respeito de alimentos saudáveis e não saudáveis, sem qualquer influência, era orientado a colar essa imagem em um dos cartazes fixados na parede.

\section{Etapa 2:}

Na segunda etapa foi realizada a ação intitulada "Lavagem correta das mãos". A atividade iniciou com um momento de apresentação, no qual cada aluno recebeu um balão revestido com glitter colorido. Foram dados 3 minutos para que eles brincassem com os balões, enquanto isso tocava de fundo a música: Lavar as Mãos do Castelo Rá Tim Bum, promovendo o momento de descontração. Então cada aluno foi convidado para dizer o seu nome e qual era o seu alimento preferido. Logo após esse momento, foi solicitado que olhassem as suas mãos, que se encontravam sujas de glitter. 0 glitter foi usado para representar as impurezas que o ser humano tem contato diariamente.

Em seguida, para reforçar a atividade foi passado o vídeo do Castelo Rá-Tim-Bum denominado lavagem das mãos, disponível na plataforma de compartilhamento de vídeos do YouTube5. Após a apresentação do vídeo foi formado um semicírculo no centro da sala de aula, onde cada um dos participantes repetiu todos os passos mostrados no vídeo. No mesmo ambiente, eles receberam em suas mãos uma pequena quantidade de álcool em gel, que representou o sabão que seria utilizado quando houvesse o procedimento de lavagem das mãos com água e sabão, assim que eles fossem destinados para o local correto. Dois facilitadores conduziram o momento, sendo que um deles utilizou duas representações de mãos feitas de EVA e a outra simulou, juntamente com os alunos, os movimentos corretos que deveriam ser realizados durante a lavagem das mãos. Ao fim dessa atividade, os alunos foram direcionados aos banheiros, para que cada um realizasse a própria lavagem das mãos, colocando em prática o que foi anteriormente ensinado.

\section{Etapa 3:}

Na terceira etapa, foi realizada a atividade intitulada "Análise sensorial dos alimentos". Como o próprio título sugere, a atividade se baseava na análise sensorial de alimentos por meio de alguns sentidos: tato, olfato e paladar. Nesta oficina os atributos referentes à aparência dos alimentos não foram avaliados, assim como também não foram avaliadas características relacionadas ao órgão do sentido da audição. Os alimentos utilizados na atividade para a análise por meio do tato foram: maçã, tomate, banana, abóbora e feijão; já para o olfato foram: mamão, banana, laranja, manga e tangerina; e para o paladar foram: mamão, banana, tomate, bolacha e cenoura. A atividade foi realizada em forma de circuito e contava com diversas estações. Em cada estação, entrava um aluno por vez e, ao concluir, ele seguia para a próxima.

Para avaliar o reconhecimento do alimento utilizando o tato, foi montada uma cabine para que os alunos colocassem uma das mãos. Eles deveriam apalpar os alimentos e dizer o nome do produto que estava sendo apresentado. As respostas foram anotadas em uma ficha individual, que continha o nome dos alimentos e o campo de resposta (acerto/erro). Em outra sala, foi realizado o teste de olfato e paladar. Todos os alunos foram previamente vendados e diferentes alimentos foram expostos para que pudessem, através da aspiração, identificar qual o produto estava sendo apresentado. Após a conclusão desta etapa, os alunos recebiam do tutor uma amostra para que pudessem degustar e verificar qual era o alimento através do paladar. A avaliação do sabor foi colocada como a última etapa visando simular a condição real de uma avaliação sensorial, em que o aroma e a textura são atributos avaliados previamente. 0 percurso que todos os escolares fizeram na realização desta oficina foi o mesmo de forma a impedir qualquer condição que interferisse o resultado final da avaliação.

\section{Etapa 4:}

A última etapa realizada foi a atividade intitulada "Horta saudável", tendo como objetivo conscientizar os alunos quanto à necessidade de práticas alimentares mais saudáveis através da implantação de uma horta suspensa. 0 propósito da horta foi para incentivar o cultivo e, consequentemente, o consumo de hortaliças produzidas pelos alunos. Os estudantes foram reunidos no ambiente, anteriormente definido para preparação da horta, onde se encontrava todo o material a ser utilizado: pallet, potes de plástico (já com furos no fundo), terra (já preparada), sementes (coentro e cebolinha), regador manual, água e pazinhas.

5 Disponivel em:<https://www.youtube.com/watch?v=ZDvA H7G1PE> . Acesso em 20 mar. 2020. 
Os alunos iniciaram a construção da horta colocando algumas pedras no fundo do pote de plástico para, assim, evitar o acúmulo de água. No próximo passo, preencheram com a terra que já se encontrava preparada e, logo depois, inseriram as sementes. Cada aluno identificou o seu pote com o nome. Ao final da atividade, um aluno irrigou toda a horta. Foi definido o plano de manejo, no qual cada dia um aluno ficou responsável por cuidar da irrigação, observação do crescimento e desenvolvimento das hortaliças.

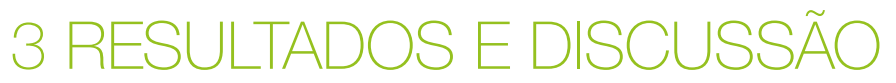

As oficinas de EAN foram realizadas com uma amostra de 15 alunos de ambos os sexos, com faixa etária de 15 a 40 anos de idade, matriculados nas turmas de escolarização, EJA e oficina na APAE do município de Palmas-TO. Primeiramente, os alunos foram expostos a uma ação que os remetessem à reflexão para escolha dos alimentos saudáveis e não saudáveis através da colagem das figuras.

Entende-se por alimentação saudável aquela que esteja apropriada aos aspectos biológicos e socioculturais dos indivíduos, estando de acordo com as necessidades de cada período da vida. Tendo em vista que os hábitos alimentares de um indivíduo refletem sua imagem, não só o corpo, como também a mente, que se desenvolve de acordo com a sua alimentação (CUNHA, 2014). No entanto, é importante destacar que a obesidade envolve diversas dimensões, entre elas a fisiológica, social e a psicológica, que resulta do desequilíbrio entre a ingestão energética e o gasto calórico. Sedentarismo, genética, questões socioeconômicas, ambientais e culturais fazem parte dos fatores que condicionam a etiologia multifatorial da obesidade (HERNANDEZ; VALENTINI, 2010).

Durante a atividade, os alunos fixaram os alimentos nos cartazes, de acordo com a sua percepção do que é saudável e não saudável. No entanto, ficou evidente que as escolhas foram feitas levando em consideração o ato de gostar ou não do alimento, fixando os alimentos mais aceitos na figura designada como saudável. Esse tipo de intervenção nutricional se tornou uma importante estratégia, uma vez que, após a organização correta das figuras nos cartazes, foi explicado aos participantes do projeto os benefícios e os malefícios de cada alimento, para que os alunos pudessem entender que as escolhas da alimentação influenciam de forma significativa na qualidade da saúde.

Foram utilizados como referência para alimentos saudáveis aqueles que apresentam teor significativo de vitaminas, fibras e minerais (frutas, verduras, leite, ovos, dentre outros). Os considerados não saudáveis foram representados por produtos com alto teor de sódio, gordura e açúcar (bacon, batata frita, biscoito recheado, refrigerante, sorvete, dentre outros) (CORREIA et al., 2016). Em geral, observou-se, nesta atividade, um grande envolvimento dos estudantes. Alguns se mostraram surpresos com a classificação que o alimento recebia, porque a referência de alimento saudável que tinham era pelo ato de gostar do alimento e não necessariamente pela qualidade nutricional.

A segunda atividade teve como objetivo abordar os passos para lavagem das mãos. Assim, foi possível destacar que somente a frequência de higienização das mãos não é o suficiente para a redução da disseminação de patógenos, necessitando também de adequada execução, sendo as mãos o principal meio de contaminação bacteriana (ANVISA, 2016). A lavagem consiste na fricção manual rigorosa de toda a superfície das mãos e dos punhos, utilizando-se sabão ou detergente, seguida de enxágue abundante em água corrente. Essa medida visa à remoção da maioria dos micro-organismos, células descamativas, pelos, suor, sujidade e oleosidade (ANVISA, 2016).

A complementação da atividade com a música foi uma estratégia de fixação do conteúdo explanado, pois ela contribuiu para o processo de aprendizagem e de desenvolvimento de aspectos cognitivos, como apresentado no estudo de Chiarelli e Barreto (2005). De forma geral, na segunda atividade, observou-se que os alunos tiveram dificuldade de coordenação motora para atender a todos os movimentos requeridos durante a lavagem correta das mãos, seja por falta de concentração, seja por se dispersarem no ambiente. Quanto aos erros percebidos na intervenção, identificou-se que os alunos não conseguiram lavar cuidadosamente as mãos, fazendo movimentos rápidos para a breve retirada do sabão, sem antes ter esfregado todas as partes das mãos. Por outro lado, todos participaram da atividade, não mostrando resistência. No entanto, cada um participou ao seu modo. Eles ficaram atentos à importância da lavagem das mãos, principalmente no que se refere à presença de micro-organismos nessa parte do corpo. Também ficaram impressionados com a possibilidade de adoecerem, caso comam alimentos contaminados, o que reforçou a importância de lavar as mãos corretamente.

A terceira atividade consistiu na avaliação do comportamento alimentar dos alunos pela análise sensorial utilizando o tato, o olfato e o paladar. A análise sensorial é um conjunto de métodos e técnicas que permite perceber, mostrar, medir, analisar, identificar e interpretar as reações das propriedades sensoriais dos alimentos mediante os sentidos da visão, olfato, paladar, tato e audição (GULARTE, 2009).

De acordo com os resultados obtidos após aplicação dos testes sensoriais, foi possível perceber a dificuldade, por parte dos alunos, quanto ao reconhecimento de alguns alimentos por meio do paladar 
(Figura 1A), sendo relevante a não identificação da cenoura e do tomate. Por meio do olfato (Figura 1B), observou-se destaque para a laranja e a tangerina, o que pode estar associado a uma confusão entre os dois alimentos ou pelo baixo consumo desses alimentos pelos alunos. Em contrapartida, foi perceptível a facilidade de reconhecimento da bolacha recheada, seguida pelo mamão e pela banana, podendo significar a presença constante desses alimentos na rotina alimentar dos alunos. Já nos testes de tato, foi notada grande facilidade de reconhecimento dos alimentos apresentados (Figura 1C). Dos 15 alunos que fizeram o teste, apenas quatro alunos não conseguiram identificar o tomate, confundindo-o com outros alimentos, tais como a manga e a laranja.

\section{Figura 1 - Dados de Análise Sensorial}

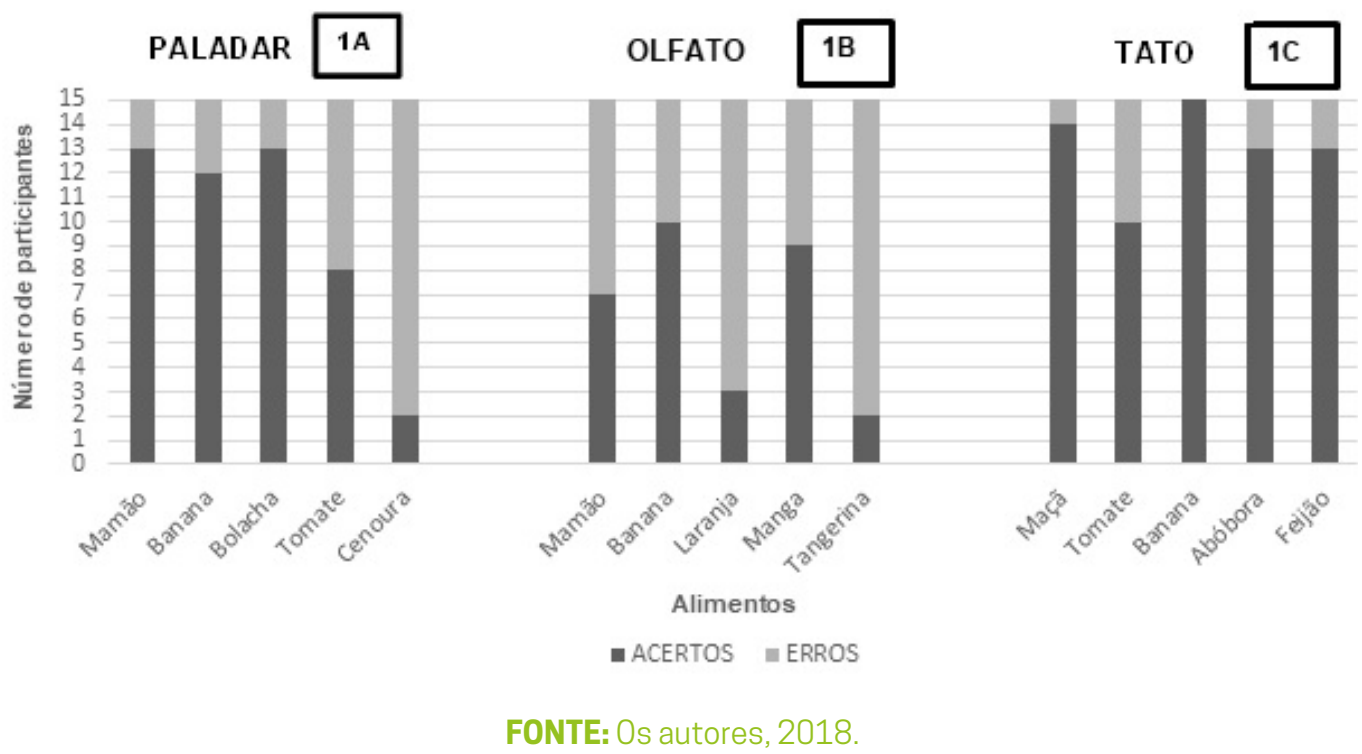

Ao considerar que as escolhas alimentares são experiências aprendidas e a aceitação de alimentos é influenciada por diferentes fatores, como é o caso da familiaridade com a comida, faz-se necessário a exposição de determinado alimento diversas vezes, com diferentes preparações, para que seja possível atingir mudanças definitivas (SULLIVAN; BIRCH, 1994). Possivelmente, os resultados da análise sensorial estão associados com a familiaridade dos alunos com os alimentos, repercutindo nas suas capacidades de discernirem uns alimentos dos outros. Os testes sensoriais exigem que as pessoas conheçam os alimentos e tenham contato com eles, para obter um maior número de acertos.

Neste caso, é importante permitir que os alunos tenham um maior contato com os alimentos, não só através de sua ingestão com avaliação do sabor, mas também despertando a avaliação sensorial pela utilização do olfato e do tato para aumentar o reconhecimento dos alimentos. 0 menor número de acertos utilizando o olfato pode ser atribuído à prática constante da súbita ingestão dos alimentos, sem a análise prévia de seu aroma, não permitindo o reconhecimento dos compostos voláteis que distinguem um alimento de outro. Vale ressaltar que este público possui características comuns, como a hipotonia muscular, na qual os processos de sucção e de deglutição ficam comprometidos, principalmente nos bebês, já as crianças poderão apresentar metabolismo mais leto e obstipação intestinal (SANTOS; SOUSA; ELIAS, 2011).

Tendo em vista os pontos citados, fazem-se necessárias práticas de EAN, em especial, o incentivo ao consumo de alimentos nutricionalmente adequados, tais como frutas e legumes, a fim de diminuir carências nutricionais e combater à obesidade. Em virtude da saúde da população com síndrome de Down receber influência de fatores intrínsecos e extrínsecos, e esse grupo geralmente possuir um estilo de vida menos ativo em relação à população que não apresenta essa deficiência, o que acarreta prejuízos à saúde e à autonomia desses indivíduos, o trabalho dos profissionais da saúde deve ser voltado à promoção de estilos de vida saudáveis, não apenas a nível individual, mas também no âmbito familiar (BRASIL, 2013).

A utilização de dinâmicas lúdicas, tais como músicas, vídeos e cartazes, para a construção da aprendizagem em qualquer tipo de intervenção sobre alimentação saudável é considerada uma ferramenta importante e efetiva, por permitir um aprendizado com entusiasmo (MAGALHÃES, 2007). Ao reforçar essa concepção sobre o lúdico no contexto escolar, Gonçalves e Ribeiro (2014) defendem a importância da ludicidade, sendo que a brincadeira, a alegria e a diversão contribuem expressivamente no ensino- 
aprendizagem. Para os autores, além de possibilitar o desenvolvimento físico, afetivo, motor e intelectual, a ludicidade pode criar ocasiões propícias à construção do conhecimento.

A última atividade proposta foi a criação de uma horta suspensa, visto que o ambiente escolar passa a ser um espaço alternativo para a aquisição de aprendizado sobre alimentação e nutrição, podendo ser considerado um laboratório vivo, no qual as crianças vivenciam diversas experiências, tornando o contato com os alimentos mais atraente e prazeroso, motivando, assim, o uso de uma alimentação mais nutritiva e saudável (PIRES et al., 2020). De acordo com Silva (2012), a horta inserida no espaço escolar pode ser uma ferramenta muito eficaz para a imbricação da interdisciplinaridade, pois essa dinâmica pressupõe a superação dos currículos disciplinares fragmentados por meio da construção dos saberes nas situações de ensino, possibilitando uma visão dialética entre o global e o local.

Portanto, na atividade 4, foi possível observar uma cumplicidade entre os próprios colegas, durante 0 preenchimento dos potes, em que o exemplo de um colega despertava a vontade do outro fazer o mesmo. Assim, os alunos não manifestaram aversão no cumprimento da atividade e sim o desejo de ir cumprindo todas as etapas, aguardando o próximo comando de atividade e questionando sempre: o que mais? Os alunos que tiveram dificuldades na condução da atividade foram orientados pelos facilitadores ou pelos demais colegas. Além disso, a intencionalidade da construção de uma horta ajudou a despertar nos alunos a importância de plantar o seu próprio alimento.

\section{CONCLUSÕES}

A aplicação das atividades de EAN compõe um pequeno início no aprendizado sobre a alimentação saudável para pessoas com deficiência, já que ações efetivas e duradouras devem ser realizadas de forma contínua e permanente. 0 ambiente escolar é um lugar propício para atividades de EAN, por conter um grupo exposto cotidianamente ao aprendizado, por isso recomenda-se que essas ações integrem o currículo escolar de forma interdisciplinar e sejam planejadas por uma equipe multiprofissional. Para tal, torna-se necessário capacitar professores, merendeiras, dirigentes escolares e outros profissionais que atuam na escola, a fim de ampliar a realização dessas atividades, pois conversas informais e atitudes simples também constituem estratégias de EAN.

Espera-se, assim, que o presente trabalho amplie a discussão sobre as estratégias adotadas de Educação Alimentar e Nutricional e ações futuras voltadas para esse público que possui uma demanda particular por atividades que possam discutir temas relacionados à alimentação e à nutrição, despertando escolhas alimentares saudáveis e, ainda, podendo contribuir na redução das doenças crônicas não transmissíveis.

A importância desta ação extensionista para a formação dos discentes do Curso de Nutrição da Universidade Federal do Tocantins está associada ao processo de formação contínua na temática da EAN, o que faz dessa experiência uma referência para os interessados em atuar nessa área do conhecimento. Portanto, as práticas extensionistas possibilitam a reflexão sobre as possiveis lacunas encontradas na formação em Nutrição, no que tange ao desenvolvimento de competências necessárias para o atendimento das demandas da sociedade, permitindo que os discentes possam assumir a responsabilidade de transformação social decorrente de suas ações, uma vez que estas práticas permitem a construção de um espaço permanente e dinâmico de interação com a sociedade de forma a reafirmar e materializar o compromisso ético e solidário das universidades públicas. A experiência relatada poderá embasar os discentes na atuação em programas de alimentação e nutrição públicos ou privados (ex. PNAE, Centro Colaborador em Alimentação e Nutrição Escolar - Cecane, programas sociais, etc.), atuação em equipamentos públicos de SAN (ex. restaurante popular, cozinha comunitária, banco de alimentos, etc.), atuação no Sistema Único de Saúde (SUS) (ex. atenção básica, vigilância sanitária, etc.), atuação no controle social (ex. Conselho de Segurança Alimentar e Nutricional - Consea, Conselho de Alimentação Escolar - CAE, Conselho Regional de Nutrição - CRN, etc.), atuação como extensionista rural (ex. agência pública e privada do serviço de extensão rural), atuação na docência na área de saúde coletiva e SAN e também na atuação com povos e comunidades tradicionais (ex. indígenas, quilombolas, etc.).

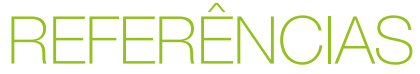

ANVISA. Segurança do paciente: higienização das mãos. Brasília: Anvisa, 2016.

BRASIL. Caderno da Atenção Básica: Programa Saúde na Escola. Brasília: Ministério da Saúde, 2009.

BRASIL. Diretrizes de Atenção à Pessoa com Síndrome de Down. Brasília: Ministério da Saúde, 2013.

Disponível em: <http://bvsms.saude.gov.br/bvs/publicacoes/diretrizes atencao pessoa sindrome down.pdf>. Acesso em: 09 abr. 2020. 
BRASIL. Guia alimentar para a população brasileira. 2. ed. Brasília: Ministério da Saúde, 2014.

BRASIL. Lei no 13.666, de 16 de maio de 2018. Altera a Lei no 9.394, de 20 de dezembro de 1996 (Lei de Diretrizes e Bases da Educação Nacional), para incluir o tema transversal da educação alimentar e nutricional no currículo escolar. Disponível em: https://bit.ly/3c3x2ug. Acesso em: 04 mar. 2021.

BRASIL. Resolução no 06, de 08 de maio de 2020. Dispõe sobre o atendimento da alimentação escolar aos alunos da educação básica no âmbito do Programa Nacional de Alimentação Escolar - PNAE. Disponível em: https://bit.ly/3sHpgw0. Acesso em: 04 mar. 2021.

CASEMIRO, Juliana Pereira; FONSECA, Alexandre Brasil Carvalho da; SECCO, Fabio Vellozo Martins. Promover saúde na escola: reflexões a partir de uma revisão sobre saúde escolar na América Latina. Revista Ciência e Saúde Coletiva, Rio de Janeiro, v. 19, n. 3, p. 829-840, 2014.

CHIARELLI, Ligia Karina Meneghetti; BARRETO, Sidirley de Jesus. A importância da musicalização na educação infantil e no ensino fundamental: a música como meio de desenvolver a integração do ser. Revista Recreart, Santiago de Compostela, n.3, 2005. Disponível em; <http://www.iacat.com/revista/recrearte/recrearte03/ musicoterapia.htm>. Acesso em: 20 mar. 2020.

CUNHA, Luana Francieli da. A importância de uma alimentação adequada na educação infantil. $32 \mathrm{f}$. Monografia de Especialização (Ensino de Ciências). Universidade Tecnológica do Paraná, Ibaiti, 2014

CORREIA, Bráulio Rocha; CARVALHO, Gleidson Giordano Pinto de; OLIVEIRA, Ronaldo Lopes; PIRES, Aureliano José Vieira; RIBEIRO, Ossival Lolato; SILVA, Robério Rodrigues; LEAO, André Gustavo. Production and quality of buf from Young bulls fed diets supplemented with peanut cake. Meat science, v. 118, p. 157-163, 2016.

GONÇALVES, Josiane Peres; RIBEIRO, Lizíria Gabriela Soares. Ludicidade no 1o ano do ensino fundamental: percepção e prática das professoras. Educação Unisinos, Campo Grande, v. 18, n. 3, p. 258-270, 2014.

GULARTE, Marcia Arocha. Manual de análise sensorial de alimentos. Pelotas: PREC, 2009.

HEBERLE, Karina. Importância e Utilização das atividades lúdicas na Educação de Jovens e Adultos. $151 \mathrm{f}$.

Trabalho de Conclusão de Pós-graduação da Universidade Tecnológica Federal do Paraná. Medianeira, 2011.

HERNANDES, Flávia; VALENTINI, Meire Pereira. Obesidade: causas e consequências em crianças e adolescentes. Conexões, Educação Física, Esporte e Saúde, Campinas v. 8, n. 3, p. 47-63, 2010.

MAGALHÃES, Cleidilene Ramos. O jogo como pretexto educativo: educar e educar-se em curso de formação em saúde. Revista Interface, Botucatu, v. 11, n. 23, p. 647-654, 2007.

MARQUES, Claudia Luiza. Metodologia do lúdico na prática docente para a melhoria da aprendizagem na educação inclusiva. Revista Eixo, Brasília, v. 1, n. 2, p. 80-91, 2012.

PIRES, Caroline Roberta Freitas; SOUSA, Diego Neves de; KATO, Hellen Christina Almeida; SANTOS, Viviane Ferreira. Metodologias aplicadas na Educação alimentar e Nutricional para o aumento do consumo de pescado na alimentação escolar: relatos de experiências. Palmas: Editora UFT, 2020.

ROSSI, Alessandra; MOREIRA, Emília Addison Machado; RAUEN, Michelle Soares. Determinantes do Comportamento Alimentar: uma revisão com enfoque na família. Revista de Nutrição, Campinas, v. 21, n. 6, p. 739-748, 2008.

SANTOS, Grazielle Gebrim; SOUSA, Juliana Barbosa; ELIAS, Bruna Cristina. Avaliação antropométrica e frequência alimentar em portadores de Síndrome de Down. Ensaios e Ciência: Ciências Biológicas, Agrárias e da Saúde, Londrina, v. 15, n. 3, p. 97-108, 2011.

SANTOS, Irani Gomes dos. Nutrição clínica, esportiva, saúde coletiva e unidades de alimentação e nutrição. São Paulo: Martinari, 2015. 
SEIXAS, Sandra lara Lopes; CORREA, Terezinha de Jesus Sirotheau; NOGUEIRA, Caroline de Souza Fortuna; ZUCHELLI, Marcelle Gonçalves. Atividades de extensão no aprimoramento do processo ensino-aprendizagem na formação de alunos do projeto: "Curso de atualização: aspectos morfofuncionais e clínicos da cabeça e pescoço” na Universidade Federal Fluminense UFF. Cidadania em ação: Revista de extensão e Cultura, Florianópolis, n. 2, v. 1, p. 1-11, 2008.

SILVA, Raimundo Paulino da. A escola enquanto espaço de construção do conhecimento. Revista Espaço Acadêmico, Maringá, n. 139, p. 83-91, 2012.

SULLIVAN, Susan; BIRCH, Leann. Infant dietary experience ad acceplance of solid foods. Pediatrics, v. 93, n. 2, p. 271-277, 1994.

ZUCHETTO, Angela Teresinha; MIRANDA, Talita Barbosa. Estado Nutricional de crianças e adolescentes com deficiências. Revista Digital, Buenos Aires, v. 16, n. 156, 2011. 